GSA Data Repository DR2016060

\title{
Is the Troodos ophiolite (Cyprus) a complete, transform fault-bounded Neotethyan ridge segment?
}

Antony Morris and Marco Maffione

\section{Data Repository - methods}

\subsection{Paleomagnetic analysis}

Natural remanent magnetizations (NRMs) of samples were investigated via alternating field (AF) demagnetization using an AGICO LDA-3A demagnetizer in 12 incremental steps from 5 to $100 \mathrm{mT}$. One twin specimen per site was thermally demagnetized with $14-16$ temperature increments from 100 to $580^{\circ} \mathrm{C}$ (or until complete demagnetization) to determine the blocking temperature(s) of the magnetic carriers. Magnetic remanences were measured at each AF or thermal demagnetization step using an AGICO JR-6A spinner magnetometer. Demagnetization data were displayed on orthogonal vector plots (Zijderveld, 1967), and remanence components were isolated via principal component analysis (Kirschvink, 1980) using Remasoft 3.0 software (Chadima and Hrouda, 2006). Site mean directions were evaluated using Fisherian statistics (Fisher, 1953) on virtual geomagnetic poles (VGPs) corresponding to the isolated characteristic remanent magnetizations (ChRMs). All VGPs at each site fell within the $45^{\circ}$ cut-off recommended by Johnson et al. (2008). Paleomagnetic quality criteria proposed by Deenen et al. (2011) were adopted to estimate the reliability of the ChRM/VGP distribution at the site level. In particular, the VGP scatter (i.e., $A_{95}$ ) obtained at each site was compared to the expected scatter induced 
by paleosecular variation (PSV) of the geomagnetic field (i.e., $A_{95 \min }-A_{95 \max }$ ) to assess whether PSV was sufficiently represented in our datasets (Deenen et al., 2011). For values of $A_{95}<A_{95 \min }$ PSV is not adequately represented, indicating either insufficient time averaging of the geomagnetic field (i.e. sampled dikes were injected in a short period of time), or remagnetization. Conversely, values of $A_{95}>A_{95 \max }$ may indicate additional (tectonic) processes responsible for the enhanced scatter of paleomagnetic directions.

\subsection{Net tectonic rotation}

Net tectonic rotation analysis describes the final (net) deformation at a paleomagnetic sampling site in terms of a single rotation about an inclined axis, which, in sheeted dike complexes, simultaneously restores dikes back to their initial (vertical) orientation and their in situ mean remanence to an appropriate reference direction. Net tectonic rotation solutions are expressed as the azimuth and plunge of the rotation axis, the magnitude and sense of the rotation, and the initial dike orientation. Key assumptions of this method (Allerton and Vine, 1987) are: (1) remanence was acquired before tilting; (2) an appropriate (coeval) reference magnetization direction may be found; (3) dikes were initially vertical; (4) no significant internal deformation has occurred.

Two solutions are generated if the dike can be restored to the vertical. In this case, additional geological evidence should be used to choose a preferred solution. If a dike cannot be restored to the vertical a single solution is obtained for the rotation axis that restores the dike to its steepest orientation. The uncertainties associated with the calculated net tectonic rotation parameters at each site are directly dependent on the errors associated with the reference magnetization vector, in situ remanence, and dike 
orientation. To quantify this uncertainty an iterative method was devised by Morris et al. (1998) and successfully applied to the study of the sheeted dikes from other areas of Troodos and other ophiolites. In this method, five potential values (mean value, plus four points located along the 95\% ellipses of confidence) are selected for each of the three input vectors used for the analysis. The 125 combinations of input vectors (5 x 5 x 5) provide 125 individual permissible net tectonic rotation solutions at a site (that define an irregular envelope providing a first-order approximation of the $95 \%$ confidence region for rotation axes) together with a frequency distribution of associated rotation angles.

\section{References}

Allerton, S., and Vine, F. J., 1987, Spreading structure of the Troodos ophiolite, Cyprus: Some paleomagnetic constraints: Geology, v. 15, no. 7, p. 593.

Chadima, M., Hrouda, F., 2006, Remasoft 3.0 a user-friendly paleomagnetic data browser and analyzer. Travaux Géophysiques XXVII, 20-21.

Deenen, M. H. L., Langereis, C. G., van Hinsbergen, D. J. J., and Biggin, A. J., 2011, Geomagnetic secular variation and the statistics of palaeomagnetic directions: Geophysical Journal International, v. 186, no. 2, p. 509-520.

Fisher, R. A., 1953, Dispersion on a sphere: Proc. R. Soc. London, v. 217, p. 295305.

Johnson, C.L., et al., 2008, Recent investigations of the 0-5 Ma geomagnetic field recorded by lava flows: Geochemistry, Geophysics, Geosystems, v. 9, Q04032, doi.org/10.1029/2007GC001696.

Kirschvink, J. L., 1980, The least-squares line and plane and the analysis of palaeomagnetic data: Geophysical Journal, Royal Astronomical Society, v. 62 , no. 3, p. 699-718.

Morris, A., Anderson, M.W., Robertson, A.H.F., 1998, Multiple tectonic rotations and transform tectonism in an intraoceanic suture zone, SW Cyprus: Tectonophysics, v. 299, no. 1-3, p. 229-253.

Zijderveld, J. D. A., 1967, AC demagnetization of rocks: Analysis of results: Methods in Paleomagnetism, p. 254-286. 
Morris and Maffione

Figure DR1

Adobe Illustrator CS5, version 15.0.0

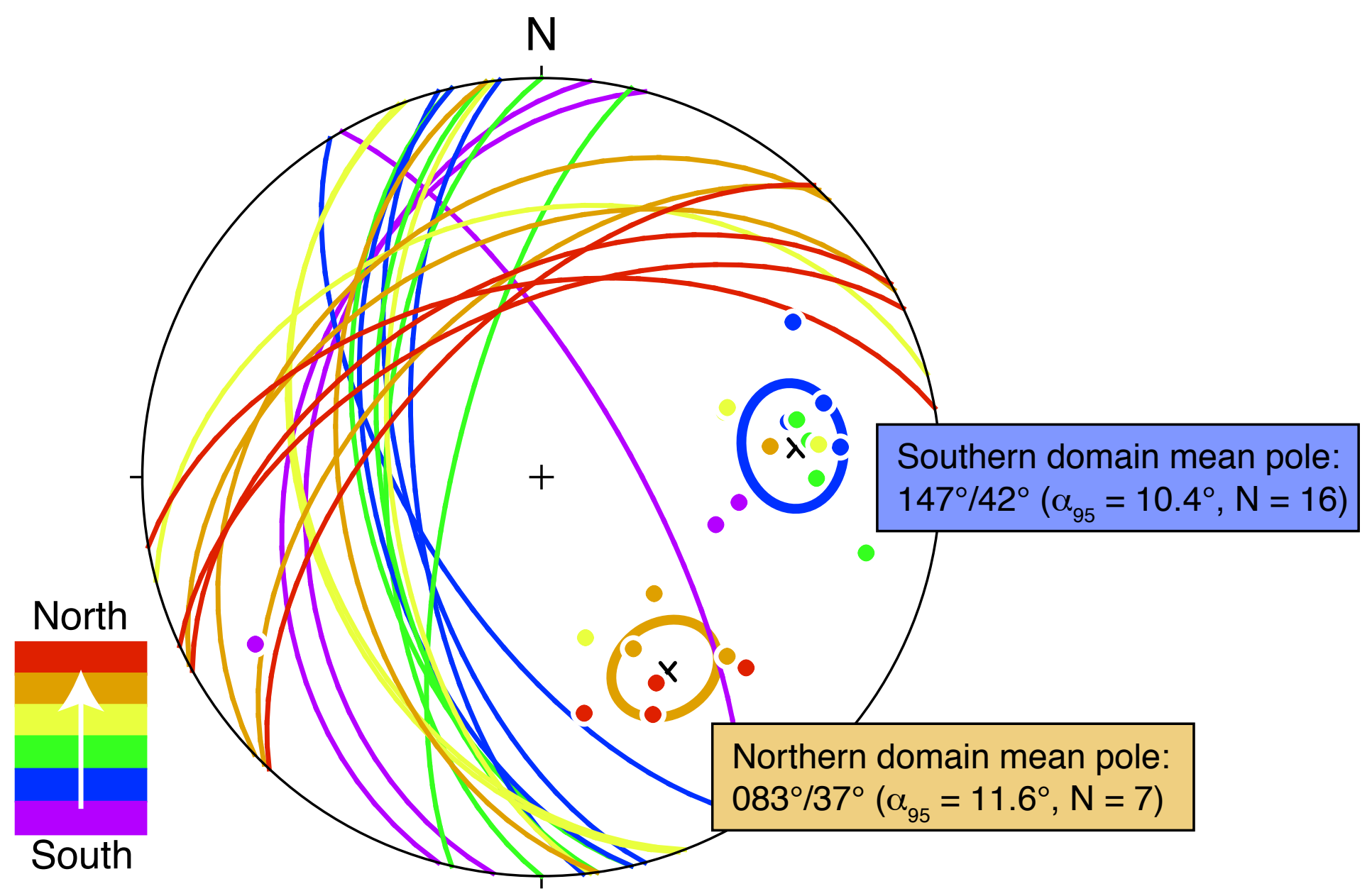

Figure DR1. Equal area stereographic projection (lower hemisphere) of in situ dike orientations within the study area, displayed as planes (great circles) and poles (dots), color-coded by increasing site latitude. Two regions characterized by different dike orientation are recognized: a northern domain with NE-SW-trending dikes, and a southern domain with mainly N-S-trending dikes. Cones of $95 \%$ confidence around the dike poles calculated separately for the northern and southern domain demonstrate statistically significant differences $\left(\sim 60^{\circ}\right)$ between the mean dike orientations in the two domains. Three sites in late dikes (see text) and two additional sites showing inconsistent dike orientations, have been excluded from the computation of mean dike orientations. 
Morris and Maffione

Figure DR2

Adobe Illustrator CS5, version 15.0.0

a

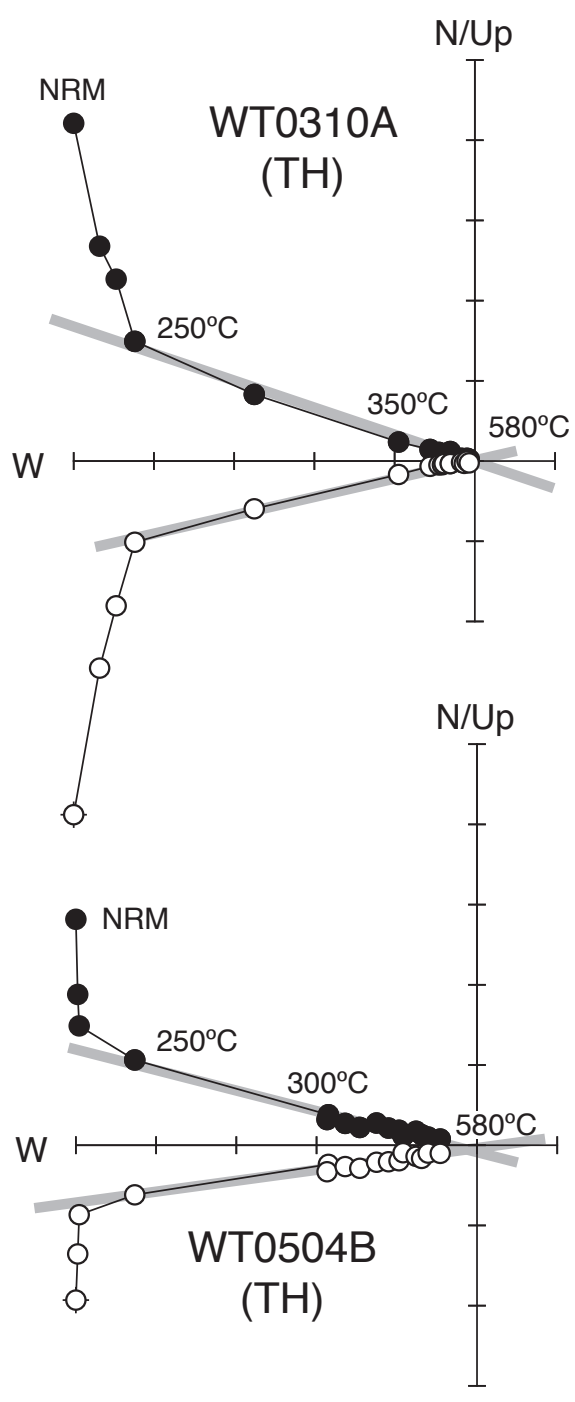

b
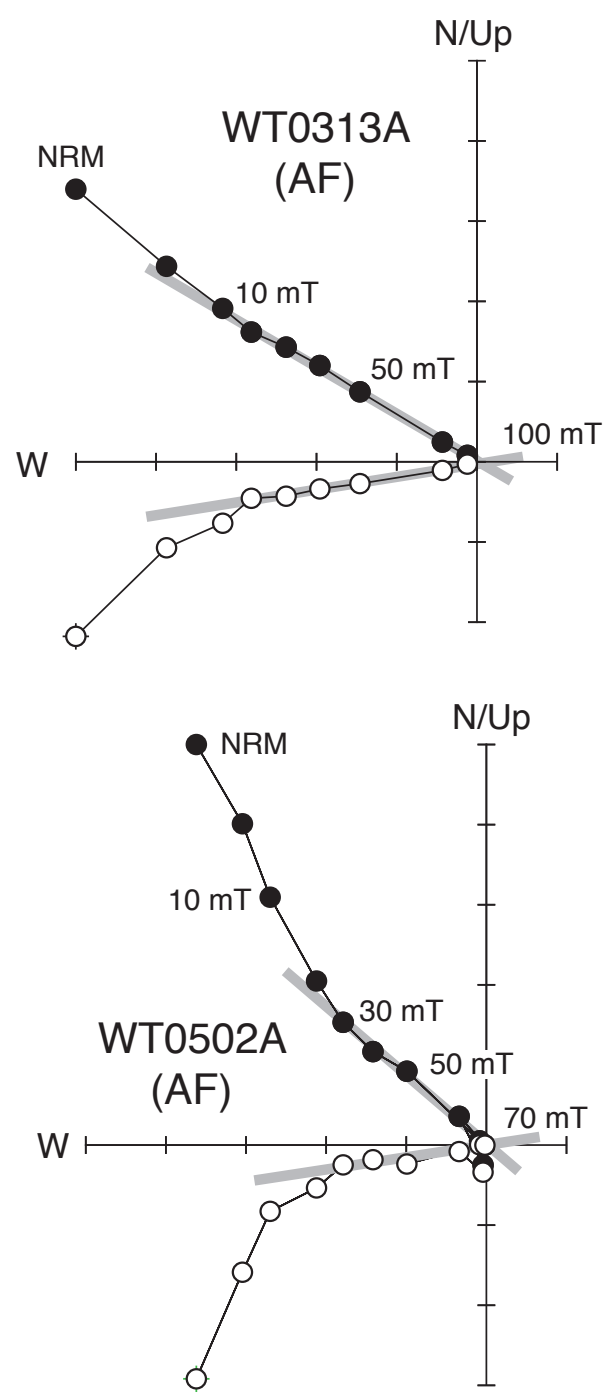

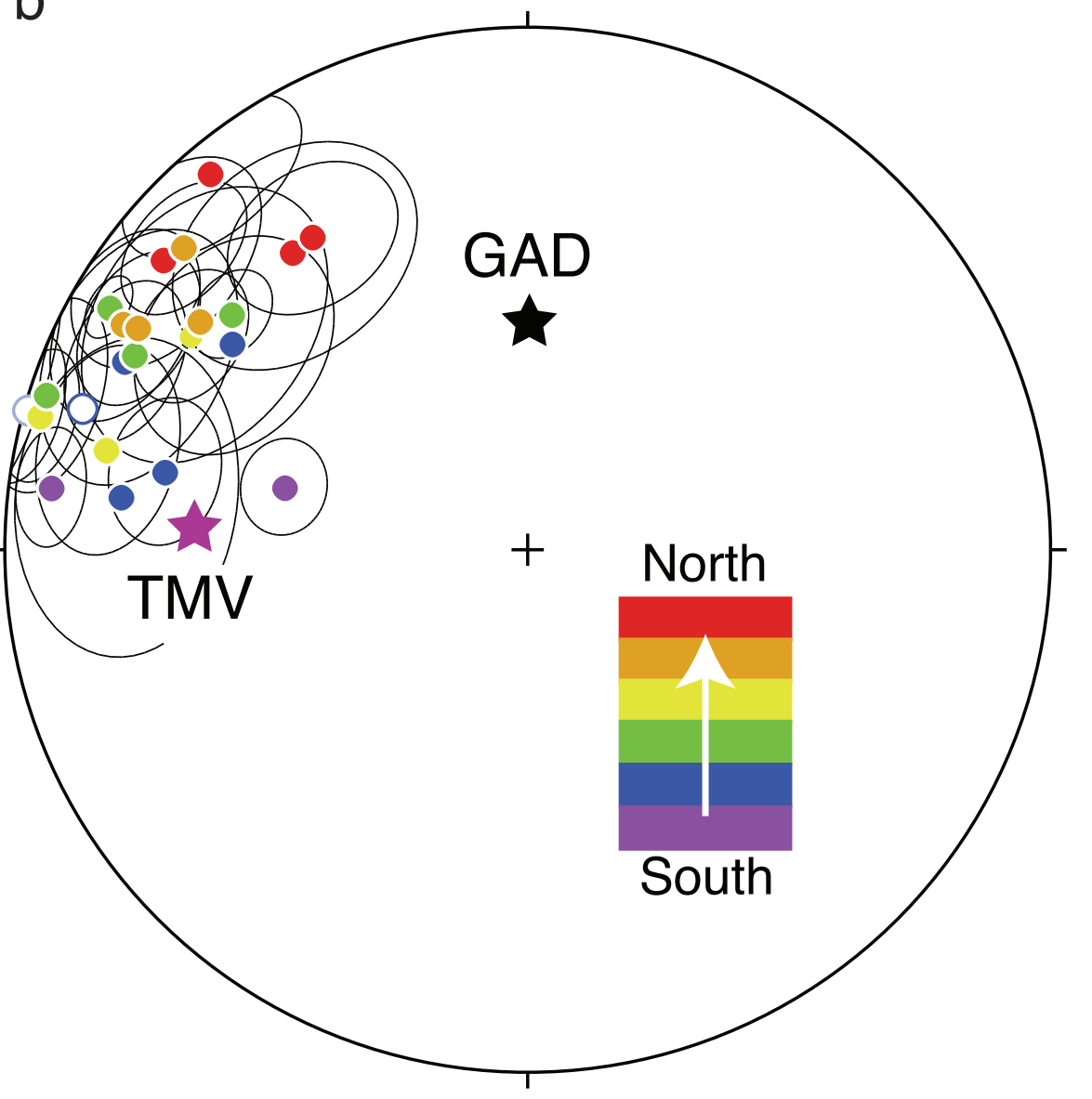

TMV: Troodos Magnetization Vector

$\mathrm{Dec} / \mathrm{Inc}=274^{\circ} / 36^{\circ}\left(\alpha_{95}=7.0^{\circ}\right)$

GAD: Geocentric Axial Dipole field direction $\mathrm{Dec} / \mathrm{lnc}=000^{\circ} / 54^{\circ}$ 
Figure DR2. (a) Representative orthogonal vector plots (in situ coordinates) for twin specimens demagnetized thermally (TH) and using alternating fields (AF). Solid/open circles are projections of the remanence vector onto the horizontal/vertical planes respectively. Demagnetization steps are in ${ }^{\circ} \mathrm{C}$ or millitesla $(\mathrm{mT})$. Gray lines are the characteristic remanent magnetizations (ChRMs) isolated in each specimen. (b) Equal area stereographic projection (lower hemisphere) of site mean directions (dots) and associated $\alpha_{95}$ cones of confidence (gray ellipses) from all sites sampled, color-coded by increasing site latitude. Colored/open symbols represent positive/negative inclinations respectively. Purple star, Troodos magnetization vector (TMV; declination/inclination $=274^{\circ} / 36^{\circ}, \alpha_{95}=7.0^{\circ} ;$ Clube and Robertson (1985)). Black star, direction of the present geocentric axial dipole field (GAD) in Cyprus $\left(D / I=000^{\circ} / 54.6^{\circ}\right)$. 


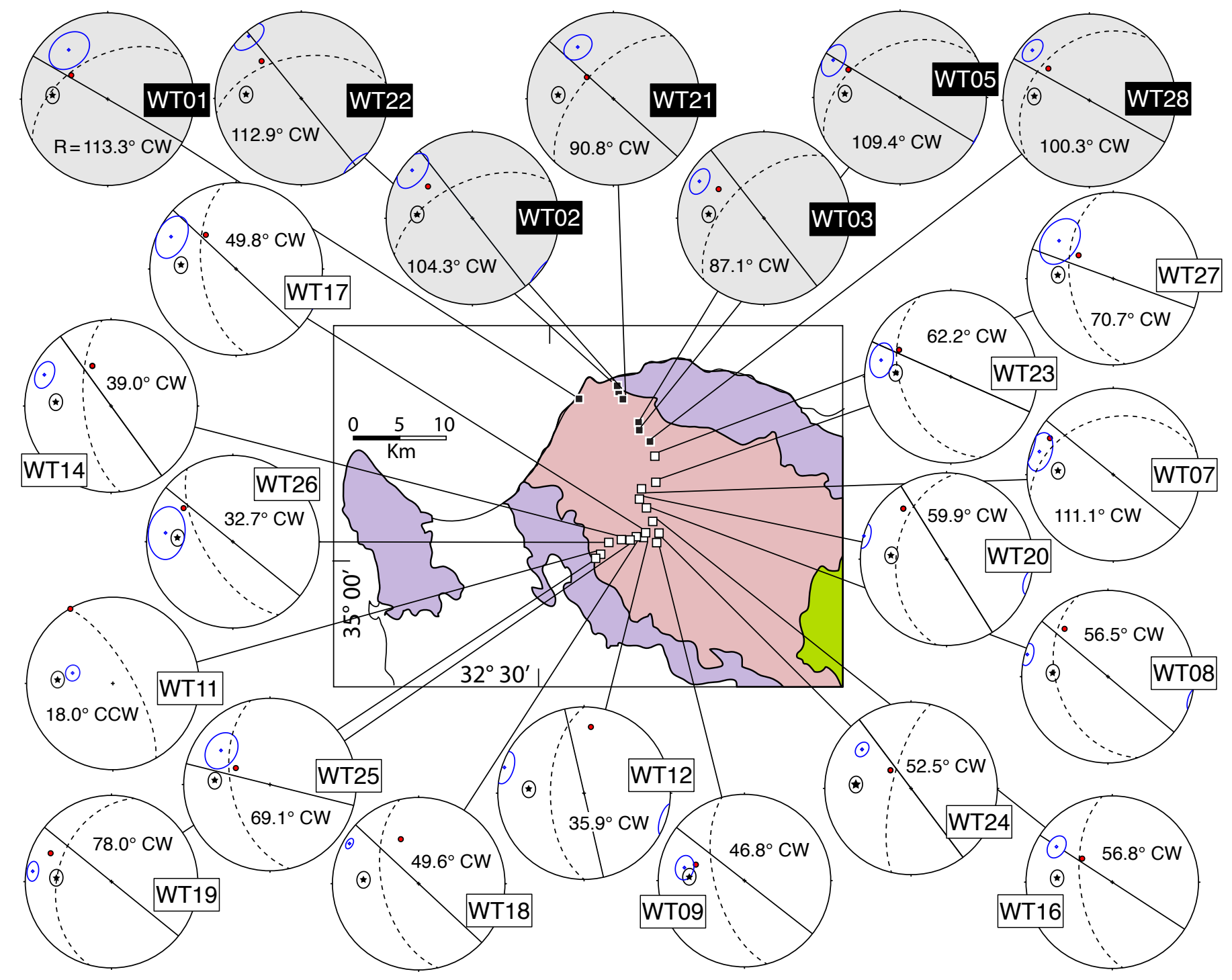

Morris and Maffione

Figure DR3

Adobe Illustrator CS5, version 15.0.0

Figure DR3. Equal area stereographic projections showing results of net tectonic rotation analysis at all sampled sites. Gray/white projections and black/white squares on the geological map indicate sites in the northern/southern domains, respectively (see text); black stars, Troodos reference direction (TMV); blue dots, in situ site mean remanence directions (with associated $95 \%$ cones of confidence); red dots, net tectonic rotation axes; $\mathrm{R}$, amount of rotation (CW, clockwise; CCW, counterclockwise). 


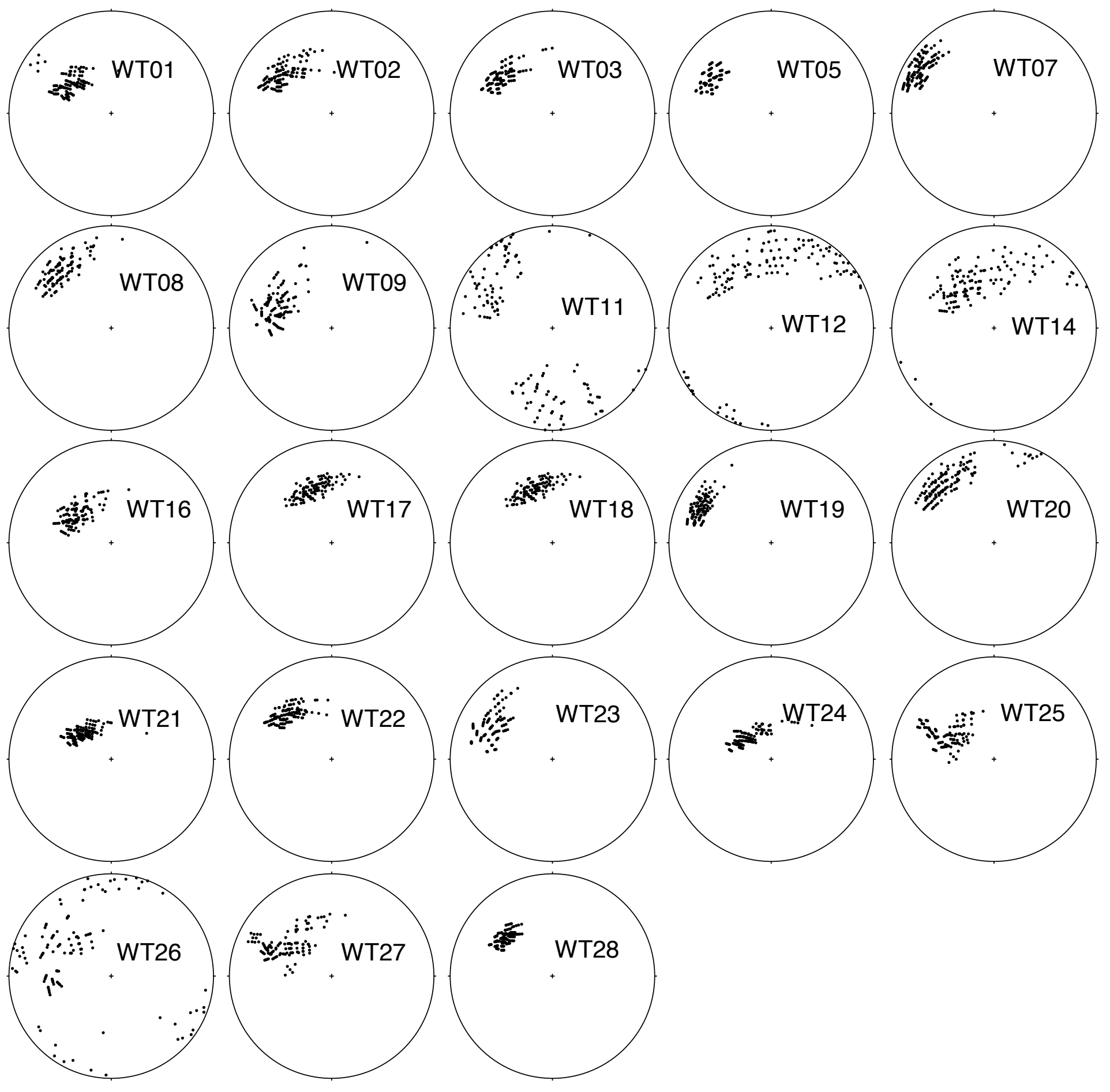

Morris and Maffione

Figure DR4

Adobe Illustrator CS5, version 15.0.0

Figure DR4. Equal area stereographic projections showing the 125 permissible rotation axes (black dots) computed by net tectonic rotation analysis at each sampling site. The scatter of the permissible rotation axes provides a first-order estimate of the error associated with the mean rotation axis calculated at each site. 

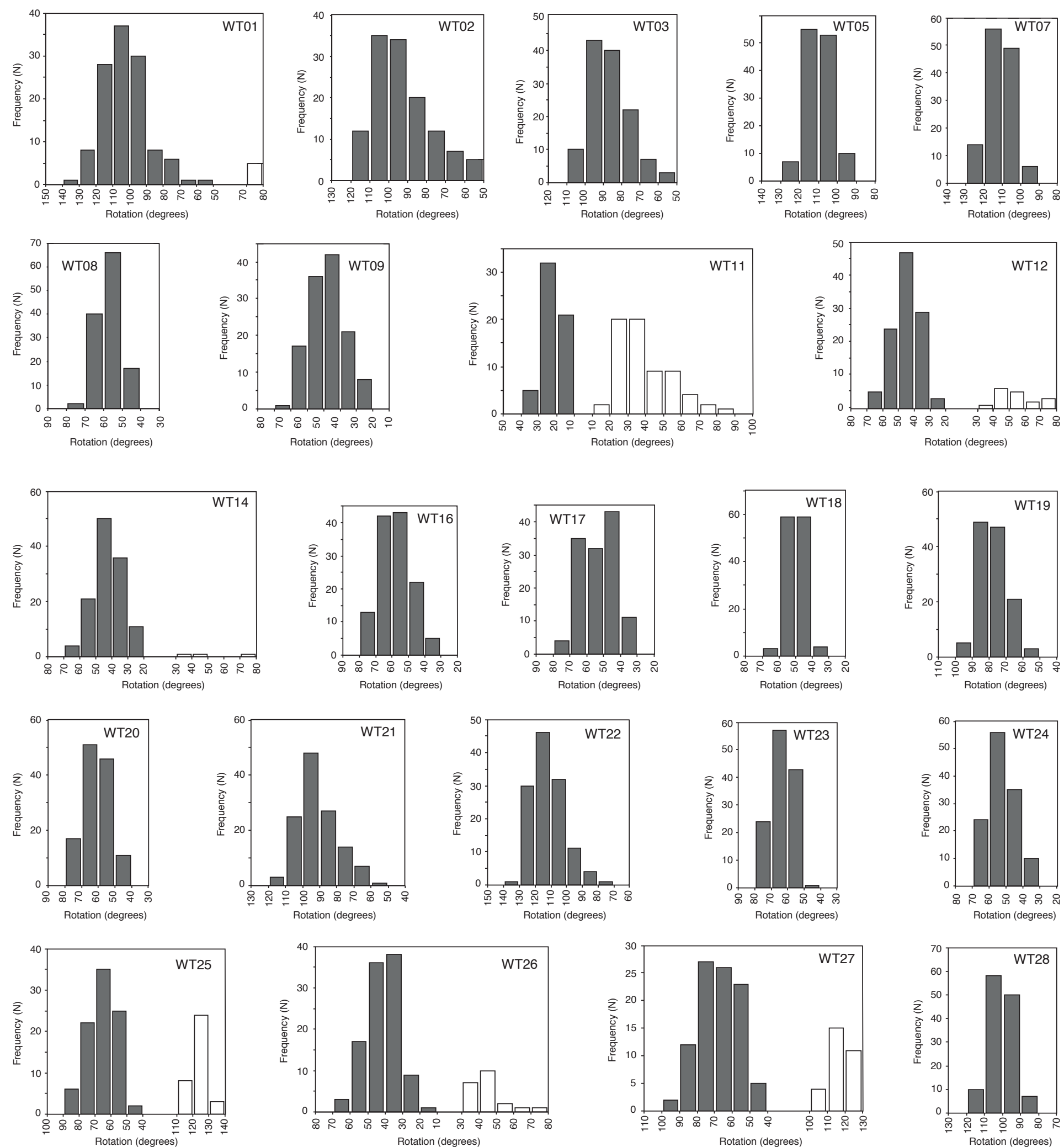

Morris and Maffione

Figure DR5

Adobe lllustrator CS5, version 15.0.0

Figure DR5. Histograms of the 125 permissible rotation magnitudes obtained at each site. Dark gray and white bars indicate $\mathrm{CW}$ and $\mathrm{CCW}$ net rotation, respectively. 
Table DR1. Paleomagnetic results from the sheeted dike complex of the western Troodos ophiolite.

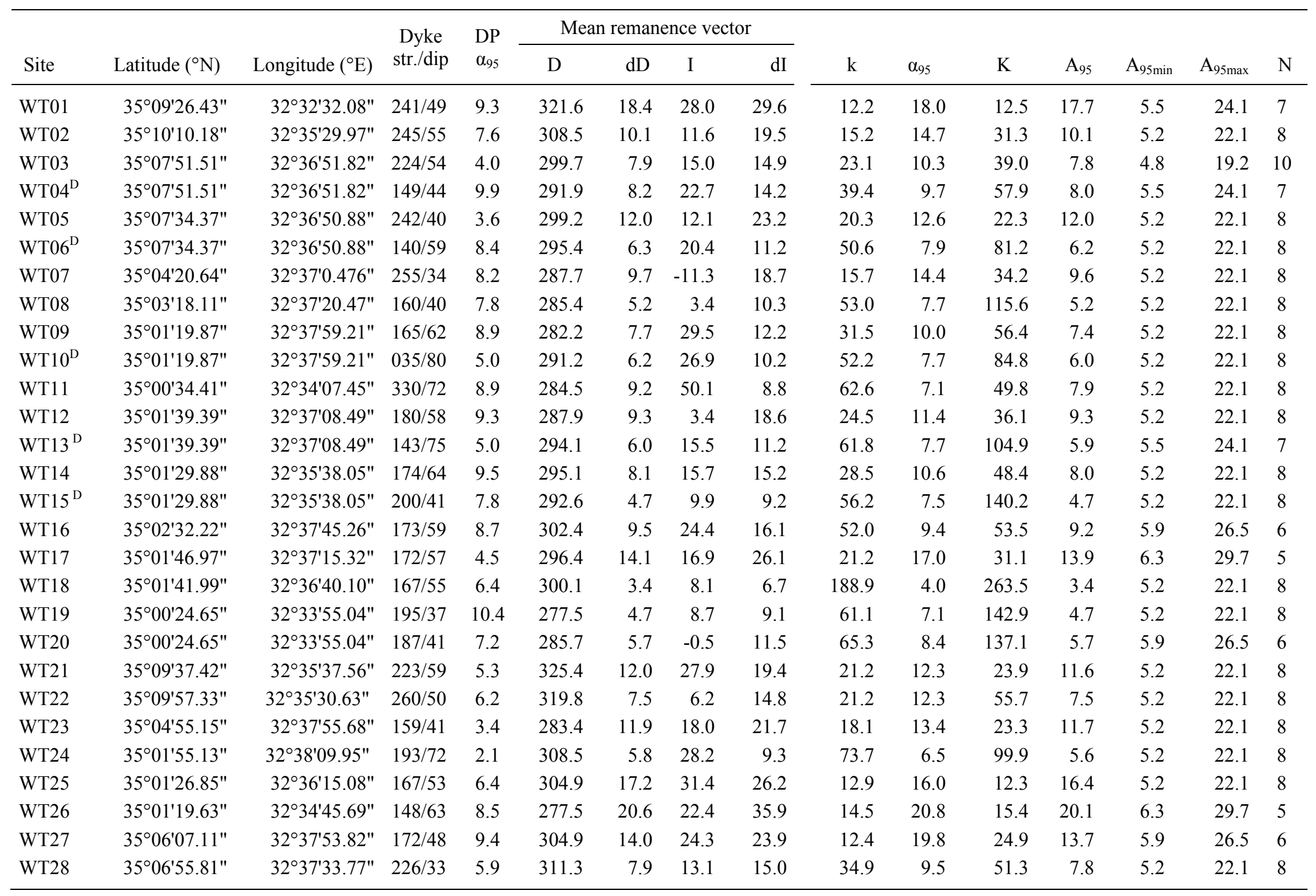

Note: ${ }^{\mathrm{D}}$ Discrete dike. Dike orientation is expressed as strike/dip. DP $\alpha_{95}, 95 \%$ cone of confidence around the calculated mean dike orientation. D, I, declination and inclination of in situ site mean remanence. $\mathrm{dD}$, dI, declination and inclination error, respectively. $\mathrm{k}, \alpha_{95}$, precision parameter and 95\% cone of confidence around the site mean characteristic remanent magnetizations (ChRMs) after Fisher (1955). K, $A_{95}$, precision parameter and $95 \%$ cone of confidence around the site mean virtual geomagnetic pole (VGP). A95min, $A_{95 m a x}$, minimum and maximum value of $\mathrm{A}_{95}$ expected from paleosecular variation (PSV) of the geomagnetic field, according to Deenen et al. (2011). N, number of total samples used for the statistics. 
Table DR2. Net tectonic rotation solutions for sheeted dikes of the western Troodos ophiolite.

\begin{tabular}{|c|c|c|c|c|c|c|c|c|c|c|c|c|}
\hline \multirow{3}{*}{ Site } & \multicolumn{6}{|c|}{ Preferred solution } & \multicolumn{6}{|c|}{ Alternate solution } \\
\hline & \multicolumn{2}{|c|}{ Rotation axis } & \multirow{2}{*}{$\mathrm{R}$} & \multirow{2}{*}{ Sense } & \multicolumn{2}{|c|}{ Initial dike } & \multicolumn{2}{|c|}{ Rotation axis } & \multirow{2}{*}{$\mathrm{R}$} & \multirow{2}{*}{ Sense } & \multicolumn{2}{|c|}{ Initial dike } \\
\hline & $\mathrm{Az}$ & Plunge & & & Strike & Dip & $\mathrm{Az}$ & Plunge & & & Strike & Dip \\
\hline \multicolumn{13}{|c|}{ Northern domain } \\
\hline WT02 & 305.6 & 36.8 & 104.3 & $\mathrm{CW}$ & 322 & 90 & 069.9 & 30.5 & 42.1 & CW & 046 & 90 \\
\hline WT22 & 313.2 & 37.0 & 112.9 & CW & 321 & 90 & 070.7 & 39 & 52.6 & CW & 047 & 90 \\
\hline WT21 & 309.2 & 57.4 & 90.8 & CW & 312 & 90 & 113.8 & 4.1 & 64.8 & CW & 056 & 90 \\
\hline WT01 & 303.2 & 48.1 & 113.3 & CW & 300 & 90 & 110.7 & 8.4 & 56.7 & CW & 068 & 90 \\
\hline WT03 & 302.6 & 37.7 & 87.1 & CW & 322 & 90 & 079.1 & 8.4 & 43.3 & CW & 046 & 90 \\
\hline WT05 & 298.3 & 32.4 & 109.4 & CW & 301 & 90 & 081.3 & 2.6 & 51.9 & CW & 067 & 90 \\
\hline WT28 & 307.8 & 39.7 & 100.3 & CW & 299 & 90 & 096.0 & 02 & 68.0 & CW & 069 & 90 \\
\hline \multicolumn{13}{|c|}{ Southern domain } \\
\hline WT27 & 303.9 & 49.9 & 70.7 & CW & 290 & 90 & 284.9 & 19.3 & 99.1 & CCW & 078 & 90 \\
\hline WT23 & 297.4 & 32.9 & 62.2 & CW & 294 & 90 & 269.9 & 23.2 & 97.6 & CCW & 074 & 90 \\
\hline WT07 & 299.9 & 16.4 & 111.1 & CW & 309 & 90 & 049.2 & 4.5 & 58.4 & CW & 060 & 90 \\
\hline WT20 & 319.4 & 23.9 & 59.9 & CW & 328 & 90 & 249.4 & 6.7 & 65.8 & CCW & 049 & 90 \\
\hline WT08 & 317.8 & 26.1 & 56.5 & CW & 310 & 90 & 263.6 & 13.9 & 93.0 & CCW & 058 & 90 \\
\hline WT16 & 308.1 & 53.5 & 56.8 & CW & 303 & 90 & 283.4 & 19.7 & 96.6 & CCW & 065 & 90 \\
\hline WT24 & 311.3 & 64.0 & 52.5 & CW & 323 & 90 & 286.4 & 13 & 73.9 & CCW & 045 & 90 \\
\hline WT17 & 318.4 & 46.1 & 49.8 & CW & 313 & 90 & 276.1 & 16.6 & 91.3 & CCW & 056 & 90 \\
\hline WT18 & 338.1 & 43.7 & 49.6 & CW & 313 & 90 & 275.8 & 11.8 & 100.0 & CCW & 055 & 90 \\
\hline WT12* & 005.9 & 23.9 & 35.9 & CW & 347 & 90 & 249.3 & 4.9 & 57.8 & CCW & 021 & 90 \\
\hline WT14* & 335.0 & 47.5 & 39.0 & CW & 324 & 90 & 273.7 & 15.4 & 85.4 & CCW & 044 & 90 \\
\hline WT25 & 295.8 & 53.8 & 69.1 & CW & 284 & 90 & 287.9 & 24.7 & 105.6 & CCW & 084 & 90 \\
\hline WT09 & 288.2 & 40.4 & 46.8 & CW & 308 & 90 & 274.6 & 29.4 & 91.2 & CCW & 060 & 90 \\
\hline WT26* & 304.3 & 31.5 & 32.7 & CW & 309 & 90 & 270.1 & 27.9 & 106.4 & CCW & 059 & 90 \\
\hline WT11* & 330.3 & 0.6 & 18.0 & CCW & 330 & 90 & 285.6 & 40.1 & 106.5 & CCW & 038 & 90 \\
\hline WT19 & 295.0 & 23.2 & 78.0 & CW & 309 & 90 & 252.8 & 18.2 & 66.2 & CCW & 059 & 90 \\
\hline
\end{tabular}

Note: Sites are listed in geographical order from north to south. Both preferred (gray area) and alternate solutions are reported. For each solution the azimuth $(\mathrm{Az})$ and plunge of the rotation axis, the rotation angle (R) and sense of rotation, and the initial dike strike and dip are listed. *, discarded sites (see text). 